\title{
Genetic Basis of Nonsyndromic Sensorineural Hearing Loss in the Sub-Saharan African Island Population of São Tomé and Príncipe: The Role of the DFNB1 Locus?
}

\author{
Cristina Caroça, ${ }^{1,2}$ Tiago Morim de Matos, ${ }^{3}$ Diogo Ribeiro, ${ }^{2}$ Vera Lourenço, Tânia Martins, \\ Paula Campelo, Graça Fialho, Susana Nunes Silva, João Paço,, ${ }^{1,2}$ and Helena Caria ${ }^{3,5}$
}

\begin{abstract}
Hearing loss (HL) is a common condition with both genetic and environmental causes, and it greatly impacts global health. The prevalence of HL is reportedly higher in developing countries such as the Sub-Saharan African island of São Tomé and Príncipe, where the deaf community is estimated to be less than $1 \%$ of the population. We investigated the role of the DFNB1 locus (GJB2 and GJB6 genes) in the etiology of nonsyndromic sensorineural hearing loss (NSSHL) in São Tomé and Príncipe. A sample of 316 individuals, comprising 136 NSSHL patients (92 bilateral, 44 unilateral) and 180 controls, underwent a clinical and audiological examination. Sequencing of the GJB2 coding region and testing for the (GJB6-D13S1830) and $\operatorname{del}(G J B 6-\mathrm{D} 13 \mathrm{~S} 1854)$ GJB6 deletions were performed. A total of 311 out of 316 individuals were successfully analyzed regarding the GJB2 and GJB6 genetic variations, respectively. The frequency of the GJB2 coding mutations in patients and controls was low. Some of those coding mutations are the most commonly found in Eurasian and Mediterranean populations and have also been identified in Portugal. None of the GJB6 deletions was present. The presence of certain coding variants in São Tomé and Príncipe suggests a non-Sub-Saharan genetic influx and supports the previously reported genetic influx from European (mainly Portuguese) ancestors. In summary, DFNB1 locus does not appear to be a major contributor to NSSHL in São Tomé and Príncipe. However, the presence of both pathogenic and likely pathogenic mutations in GJB2 suggests that GJB2-related NSSHL might still occur in this population, warranting further research on GJB2 testing in NSSHL cases.
\end{abstract}

\section{Introduction}

$\mathbf{H}$ EARING LOSS (HL) is a condition that is an outcome of both environmental and genetic factors. The prevalence of HL is higher in certain developing countries such as many African countries. In São Tomé and Príncipe, the deaf community is estimated to comprise less than $1 \%$ of the population based on the National Institute of Statistic of São Tomé and Príncipe (INE, 2014). Mutations in the GJB2 gene (encoding connexin 26) are responsible for a significant proportion of nonsyndromic hearing loss (NSHL) cases in several populations. Two large deletions, del(GJB6-D13S1830) and $\operatorname{del}(G J B 6-\mathrm{D} 13 \mathrm{~S} 1854)$, truncating the GJB6 gene (encoding connexin 30), are also responsible for NSHL in some populations, being mostly found in trans with GJB2 mutations (del Castillo et al., 2003, 2005). These genes map to $13 \mathrm{q} 11-\mathrm{q} 12$, and both of them are located within the DFNB1 locus, with the first locus defined for nonsyndromic autosomal recessive HL. Loci for nonsyndromic autosomal recessive HL are designated by DFNB followed by a suffix integer (Smith and Van Camp, 1998). Mutations in GJB2 reportedly do not play a significant role in the etiology of HL in Sub-

\footnotetext{
${ }^{1}$ Otolaryngology Department, Nova Medical School/Faculty of Medical Sciences, Universidade Nova de Lisboa, Lisboa, Portugal.

${ }^{2}$ Hospital CUF Infante Santo, Otolaryngology Department, Hospital CUF Infante Santo, Lisboa, Portugal.

${ }^{3}$ Deafness Research Group, Biomedicine and Translational Research, BioISI, Faculty of Sciences, University of Lisbon, Lisbon, Portugal.

${ }^{4}$ Centre for Toxicogenomics and Human Health (ToxOmics), NOVA Medical School, Faculty of Medical Sciences, Universidade Nova de Lisboa, Lisboa, Portugal.

${ }^{5}$ School of Health, Polytechnic Institute of Setubal, Setubal, Portugal.
} 
Saharan African populations or their descendant populations (Bosch et al., 2014b; Javidnia et al., 2014; Lasisi et al., 2014; Shan et al., 2010). The role of $\operatorname{del}(G J B 6-\mathrm{D} 13 \mathrm{~S} 1830)$ GJB6 large deletion in NSHL in these populations is so far null (Bosch et al., 2014a; Kabahuma et al., 2011; Samanich et al., 2007; Shan et al., 2010). Regarding the del(GJB6-D13S1854) GJB6 deletion, its presence has been investigated in Nigerian HL patients (Lasisi et al., 2014) and in HL patients of a predominantly Caribbean Hispanic and African descent (Shan et al., 2010), without positive results.

São Tomé and Príncipe, a former Portuguese colony, was formerly settled first by people from different regions of SubSaharan Africa, mostly slaves from the Gulf of Guinea, Congo, and Angola, brought to work in local plantations, and, to a minor extent, Portuguese who were involved in the slave trade between Africa and the Americas. In the first centuries after the discovery of São Tomé and Príncipe, besides the Portuguese, other Europeans were involved in the slave trade along the coast of Africa, namely the French, Spanish, Dutch, and English (Neves, 1989). In fact, São Tomé and Príncipe's population has been shown to present $10.7 \% \pm 0.9 \%$ of European (mainly Portuguese) admixture (Tomás et al., 2002). Therefore, a putative role of $G J B 2$, or even of the $\operatorname{del}(G J B 6-\mathrm{D} 13 \mathrm{~S} 1830)$ and del(GJB6-D13S1854) large GJB6 deletions, in the HL observed in São Tomé and Príncipe might potentially be anticipated.

The aim of the present study was to examine the genetic basis of HL in this understudied Sub-Saharan African island population, and so as to obtain a broader insight on the role of genetic contributions to this important disease impacting global health.

\section{Methods and Materials}

\section{Subjects}

A total of 316 individuals (136 HL patients and 180 controls), all of whom were born in São Tomé and Príncipe, ranging from 2 to 35 years old, participated in this study. The subjects were recruited during consultation provided by the humanitarian missions in São Tomé and Príncipe, at hospitals, schools, and a hotel, over a period from February 2012 to May 2014, constituting a convenience sample. All patients and controls answered a clinical questionnaire identifying risk factors (family history of HL, consanguinity, malaria infection, prenatal and perinatal history, and history of other infections), clinical history, and otolaryngology observation.

The patients presented with mild to profound nonsyndromic sensorineural hearing loss (NSSHL), which was bilateral $\mathrm{HL}$ in 92 individuals and unilateral HL in 44 individuals. All the control individuals had normal hearing in both ears. The patients and control samples did not display a significant difference in gender $(p=0.233)$ and age $(p=0.271)$.

The classification of HL was adopted from the World Health Organization (WHO, 2013). It considers the mean value of hearing threshold (considering the $0.5,1,2$, and $4 \mathrm{kHz}$ frequencies) in the better ear. The individual has HL when the best ear presents a hearing threshold higher than 25 $\mathrm{dB}$ and is graded after that with mild (26-40 dB), moderate (41-60 dB), severe $(61-80 \mathrm{~dB})$, and profound $(81 \mathrm{~dB}$ or greater) (WHO, 2013).

The project was reviewed and approved by the Medical Ethics Committee of São Tomé and Príncipe and the Ethics Research Committee NMS|UNL ( $\left.{ }^{\circ} 02 / 2014 / C E F C M\right)$.

\section{Audiological examination}

All 316 individuals were evaluated regarding their hearing status with a pure tone audiogram-Madsen Midimate 622 or auditory brainstem response-Vivosonic Integrity V500 audiometer depending on collaboration. The audiometric exams were carried out without an audiometric cabin, with earphones TDH39, in a closed room, with a level of noise measured by iPhone de SchabelDoesIT GbR, Munich, Germany (version 1.0.0), considered acceptable, based on ANSI S3.1-1999 (R2013). Electrophysiological thresholds were translated into the audiometric thresholds for frequencies 2 and $4 \mathrm{kHz}$, without applying any correction factor (Gorga et al., 1985, 2006; Jerger and Mauldin, 1978; van de Drift et al., 1987).

\section{DFNB1 molecular analysis}

Peripheral blood samples were collected in Guthrie paper cards after informed consent had been signed. Approval of the Medical Ethics Committee was also obtained. Genomic DNA was extracted from each blood sample by using a commercially available kit (QIAamp ${ }^{\circledR}$ DNA micro kit; Qiagen) according to the manufacturer's instructions. All DNA samples were stored at $-20^{\circ} \mathrm{C}$ until analysis.

Of the 316 subjects, 311 were successfully analyzed by sequencing regarding the GJB2 coding region, and by multiplex polymerase chain reaction (PCR) (del Castillo et al., 2005) regarding the presence of the two GJB6 large deletions, $\operatorname{del}(G J B 6-\mathrm{D} 13 \mathrm{~S} 1830)$ and $\operatorname{del}(G J B 6-\mathrm{D} 13 \mathrm{~S} 1854)$. These 311 individuals comprise 134 patients (90 bilateral and 44 unilateral) and 177 controls, matched by sex and age. PCR amplification and sequencing of the coding region of the GJB2 gene was performed using previously described primers (Matos et al., 2010). The GJB2 fragment that was amplified comprises the coding region and flanking noncoding regions, including the acceptor splice site. However, the extension of the sequence obtained beyond the coding region was variable, not allowing results from the acceptor splice site for all the subjects.

All electrophoretograms were visually inspected; the lowquality extremities were trimmed off; and heterozygosities were marked, using the Chromas Lite software (v.2.01). The resulting analyzed and edited sequences were copied from Chromas Lite in Fasta format and blasted against the reference sequence NG_008358.1 using NCBI's Blast program (suite 2-sequences). All the variants described here were named according to the recommendations of the Human Genome Variation Society.

\section{Statistical analyses}

A chi-square test was performed, and $p$-values were calculated using the SPSS v.20 software. When chi-square was not possible, we adopted Fisher's exact test. Hardy-Weinberg equilibrium test was performed using Court Lab's HW calculator. This test was only performed for c. $* 84 \mathrm{~T}>\mathrm{C}, \mathrm{c} .{ }^{*} 104 \mathrm{~A}>\mathrm{T}$, and $c{ }^{*} 111 \mathrm{C}>\mathrm{T}$, since these were the only variants whose respective genotypes were all observed in five or more individuals.

\section{Results}

Insofar as the GJB2 sequencing is concerned, all the analyzed subjects were sequenced between c.- 2 and c.*6 positions, although most sequences extended, with quality, several nucleotides before c.-2 and after c.*6. The sequencing results 
Table 1. GJB2 Coding Variants Identified in Patients and Controls (All in Heterozygosity) and Respective Carrier Frequencies

\begin{tabular}{llll}
\hline GJB2 coding variants & Bilateral $H L$ & Unilateral HL & Controls \\
\hline c.35delG (p.Gly12Valfs) & $0 / 90$ & $0 / 44$ & $\mathbf{1 / 1 7 7}(\mathbf{0 . 2 8 \%})$ \\
c.101T $>$ C (p.Met34Thr) & $\mathbf{1 / 9 0}(\mathbf{0 . 5 6 \%})$ & $0 / 44$ & $0 / 177$ \\
c.109G $>$ A (p.Val37Ile) & $0 / 90$ & $0 / 44$ & $\mathbf{1 / 1 7 7}(\mathbf{0 . 2 8 \%})$ \\
c.186C $>$ T (p.Asn62 $=)$ & $0 / 90$ & $0 / 44$ & $\mathbf{1 / 1 7 7}(\mathbf{0 . 2 8 \%})$ \\
c.225G $>$ T (p.Arg75 $=)$ & $\mathbf{1 / 9 0}(\mathbf{0 . 5 6 \%})$ & $0 / 44$ & $\mathbf{5 / 1 7 7}(\mathbf{1 . 4 1 \%})$ \\
c.380G $>$ A (p.Arg127His) & $\mathbf{1 / 9 0}(\mathbf{0 . 5 6 \%})$ & $\mathbf{1})$ & $\mathbf{1 7 7 7}(\mathbf{0 . 2 8 \%})$ \\
c.457G $>$ A (p.Val153Ile) & $0 / 90$ & $0 / 44$ & $\mathbf{1 / 1 7 7}(\mathbf{0 . 2 8 \%})$ \\
c.499G $>$ A (p.Val167Met) & $\mathbf{1 / 9 0}(\mathbf{0 . 5 6 \%})$ & $\mathbf{1 / 1 7 7}(\mathbf{0 . 2 8 \%})$ \\
Frequency of mutated alleles & $4 / 180(2.22 \%)$ & $1 / 88(1.13 \%)$ & $11 / 354(3.11 \%)$ \\
\hline
\end{tabular}

HL, hearing loss.

Boldface $=$ carrier frequencies $>0$.

allowed for the identification of eight coding variants (Table 1) and 10 noncoding variants (Table 2) in patients and/or controls.

\section{Coding variants of GJB2}

Eight different coding variants, all in heterozygosity, have been identified in this study, in patients and/or control individuals (Table 1). None of these patients harbored any mutation in the acceptor splice site.

\section{Noncoding variants of GJB2}

We have identified 10 noncoding variants in the subjects of this study, being the genotyping results presented in Table 2 . The most commonly identified variant in bilateral and unilateral HL patients and controls was c. $* 84 \mathrm{~T}>\mathrm{C}$, presenting in the latter group an allelic frequency of $51.36 \%$. This variant as well as c.*104A $>\mathrm{T}$ and $\mathrm{c} \cdot{ }^{*} 111 \mathrm{C}>\mathrm{T}$ are in HardyWeinberg equilibrium in the control group.

Table 2. GJB2 Noncoding Variants Identified in the Subjects and Respective Genotypic Frequencies

\begin{tabular}{|c|c|c|c|c|}
\hline $\begin{array}{l}\text { GJB2 noncoding } \\
\text { variants }\end{array}$ & Genotypes & Bilateral HL & Unilateral HL & Controls \\
\hline c. $-22-12 \mathrm{C}>\mathrm{T}$ & $\begin{array}{l}\text { CC } \\
\text { CT } \\
\text { TT }\end{array}$ & $\begin{array}{cc}59.4 \% & (19 / 32) \\
31.3 \% & (10 / 32) \\
9.4 \% & (3 / 32)\end{array}$ & $\begin{array}{r}60 \%(6 / 10) \\
40 \%(4 / 10) \\
0 \%(0 / 10)\end{array}$ & $\begin{array}{cc}66.7 \% & (26 / 39) \\
30.8 \% & (12 / 39) \\
2.6 \% & (1 / 39)\end{array}$ \\
\hline c. $-15 \mathrm{C}>\mathrm{T}$ & $\begin{array}{l}\text { CC } \\
\text { CT } \\
\text { TT }\end{array}$ & $\begin{array}{c}82.7 \%(67 / 81) \\
16 \%(13 / 81) \\
1.2 \%(1 / 81)\end{array}$ & $\begin{aligned} 85.7 & (36 / 42) \\
14.3 \% & (6 / 42) \\
0 \% & (0 / 42)\end{aligned}$ & $\begin{aligned} 88 \% & (146 / 166) \\
11.4 \% & (19 / 166) \\
0.6 \% & (1 / 166)\end{aligned}$ \\
\hline c. $-14 \mathrm{G}>\mathrm{A}$ & $\begin{array}{l}\text { GG } \\
\text { GA } \\
\text { AA }\end{array}$ & $\begin{aligned} 98.8 \% & (80 / 81) \\
1.2 \% & (1 / 81) \\
0 \% & (0 / 81)\end{aligned}$ & $\begin{array}{c}100 \%(43 / 43) \\
0 \%(0 / 43) \\
0 \%(0 / 43)\end{array}$ & $\begin{array}{c}99.4 \%(165 / 166) \\
0.6 \%(1 / 166) \\
0 \%(0 / 166)\end{array}$ \\
\hline c. $-7 \mathrm{G}>\mathrm{A}$ & $\begin{array}{l}\text { GG } \\
\text { GA } \\
\text { AA }\end{array}$ & $\begin{array}{c}100 \%(88 / 88) \\
0 \%(0 / 88) \\
0 \%(0 / 88)\end{array}$ & $\begin{array}{c}100 \%(44 / 44) \\
0 \%(0 / 44) \\
0 \%(0 / 44)\end{array}$ & $\begin{array}{c}99.4 \%(175 / 176) \\
0.6 \%(1 / 176) \\
0 \%(0 / 176)\end{array}$ \\
\hline c. $-6 \mathrm{~T}>\mathrm{A}$ & $\begin{array}{l}\text { TT } \\
\text { TA } \\
\text { AA }\end{array}$ & $\begin{array}{c}100 \%(89 / 89) \\
0 \%(0 / 89) \\
0 \%(0 / 89)\end{array}$ & $\begin{array}{c}100 \%(44 / 44) \\
0 \%(0 / 44) \\
0 \%(0 / 44)\end{array}$ & $\begin{array}{c}97.7 \%(172 / 176) \\
2.3 \%(4 / 176) \\
0 \%(0 / 176)\end{array}$ \\
\hline c. $* 78 \mathrm{~A}>\mathrm{T}$ & $\begin{array}{l}\text { AA } \\
\text { AT } \\
\text { TT }\end{array}$ & $\begin{aligned} 97.6 \% & (80 / 82) \\
2.4 \% & (2 / 82) \\
0 \% & (0 / 82)\end{aligned}$ & $\begin{array}{c}100 \% \\
0 \%(40 / 40) \\
0 \%(0 / 40) \\
0 \%(0)\end{array}$ & $\begin{array}{c}100 \% \\
0 \%(152 / 152) \\
0 \%(0 / 152) \\
0 \% 152)\end{array}$ \\
\hline c. $* 84 \mathrm{~T}>\mathrm{C}$ & $\begin{array}{l}\text { TT } \\
\text { TC } \\
\text { CC }\end{array}$ & $\begin{array}{ll}21.3 \% & (17 / 80) \\
36.3 \% & (29 / 80) \\
42.5 \% & (34 / 80)\end{array}$ & $\begin{aligned} 30 \% & (12 / 40) \\
47.5 \% & (19 / 40) \\
22.5 \% & (9 / 40)\end{aligned}$ & $\begin{array}{l}24.5 \%(36 / 147) \\
48.3 \%(71 / 147) \\
27.2 \%(40 / 147)\end{array}$ \\
\hline c. $* 96 \mathrm{~A}>\mathrm{G}$ & $\begin{array}{l}\text { AA } \\
\text { AG } \\
\text { GG }\end{array}$ & $\begin{array}{c}100 \%(54 / 54) \\
0 \%(0 / 54) \\
0 \%(0 / 54)\end{array}$ & $\begin{array}{c}100 \%(29 / 29) \\
0 \%(0 / 29) \\
0 \%(0 / 29)\end{array}$ & $\begin{array}{c}99.2 \%(122 / 123) \\
0.81 \%(1 / 123) \\
0 \%(0 / 123)\end{array}$ \\
\hline c. $* 104 \mathrm{~A}>\mathrm{T}$ & $\begin{array}{l}\text { AA } \\
\text { AT } \\
\text { TT }\end{array}$ & $\begin{aligned} 57.7 \% & (30 / 52) \\
40.4 \% & (21 / 52) \\
1.9 \% & (1 / 52)\end{aligned}$ & $\begin{array}{cc}79.3 \% & (23 / 29) \\
17.2 \% & (5 / 29) \\
3.4 \% & (1 / 29)\end{array}$ & $\begin{array}{c}68.1 \%(79 / 116) \\
29.3 \%(34 / 116) \\
2.6 \%(3 / 116)\end{array}$ \\
\hline c. $* 111 \mathrm{C}>\mathrm{T}$ & $\begin{array}{l}\text { CC } \\
\text { CT } \\
\text { TT }\end{array}$ & $\begin{array}{cc}57.1 \% & (28 / 49) \\
42.9 \% & (21 / 49) \\
0 \% & (0 / 49)\end{array}$ & $\begin{array}{c}79.3 \% \\
17.2 \%(23 / 29) \\
3.4 \%(1 / 29)\end{array}$ & $\begin{aligned} 67 \% & (75 / 112) \\
30.4 \% & (34 / 112) \\
2.7 \% & (3 / 112)\end{aligned}$ \\
\hline
\end{tabular}


Table 3. Genotypic Distribution Regarding THE C.*84T $>$ C VARIANT In Controls and Patients with Bilateral, Severe, or Profound Hearing Loss (ChI-SQuare Test; $P=0.005$ )

\begin{tabular}{llllr}
\hline & \multicolumn{4}{c}{$c . * 84 T>C$} \\
\cline { 2 - 5 } & $T T$ & $T C$ & $C C$ & Total \\
\hline Controls & 36 & 71 & 40 & 147 \\
Expected count & 38.4 & 61.3 & 47.3 & \\
Patients & 16 & 12 & 24 & 52 \\
Expected count & 13.6 & 21.7 & 16.7 & \\
Total & 52 & 83 & 64 & 199 \\
\hline
\end{tabular}

We have observed a statistically significant difference in the distribution of genotypes regarding c. $* 84 \mathrm{~T}>\mathrm{C}$ between bilateral HL patients and controls when considering only the cases with severe and profound deafness (Table $3 ; p=0.005$ ). When also including the moderate bilateral HL patients, the difference in genotypic distribution did not remain statistically significant for the $\mathrm{c} .{ }^{* 84 \mathrm{~T}}>\mathrm{C}$ variant $(p=0.101)$.

\section{GJB6 deletions}

The del(GJB6-D13S1830) and $\operatorname{del}(G J B 6-\mathrm{D} 13 \mathrm{~S} 1854)$ GJB6 deletions have not been identified in the 134 patients (90 bilateral +44 unilateral) or 177 controls analyzed.

Table 4. All GJB2 Variants Identified in This Study and the Populations, Per the 1000 Genomes Project (Phase 3), in Which the Attendant Variants Have Been Observed

\begin{tabular}{|c|c|c|c|c|}
\hline GJB2 variant & $d b S N P I D$ & $\begin{array}{l}\text { Change at } \\
\text { protein level/ } \\
\text { Location }\end{array}$ & Effect & $\begin{array}{l}1000 \text { genomes project } \\
\text { (phase 3) populations }^{\mathrm{a}}\end{array}$ \\
\hline c. $-22-12 \mathrm{C}>\mathrm{T}$ & rs9578260 & Intron & Polymorphism $^{\mathrm{b}}$ & $\begin{array}{l}\text { ACB, ASW, CLM, ESN, ITU, LWK, MSL, } \\
\text { MXL, PEL, PUR, YRI }\end{array}$ \\
\hline c. $-15 \mathrm{C}>\mathrm{T}$ & rs72561725 & 5'UTR & Polymorphism ${ }^{\mathrm{b}}$ & $\begin{array}{l}\text { ACB, ASW, CEU, CLM, ESN, GWD, LWK, } \\
\text { MSL, MXL, PUR, YRI }\end{array}$ \\
\hline c. $-14 \mathrm{G}>\mathrm{A}$ & rs367567291 & 5'UTR & Unknown & n.a. \\
\hline c. $-7 \mathrm{G}>\mathrm{A}$ & rs398123813 & 5'UTR & Unknown & n.a. \\
\hline c. $-6 \mathrm{~T}>\mathrm{A}$ & rs 148136545 & 5'UTR & Unknown & ASW, CLM, ESN, LWK, MSL, PUR \\
\hline c. $35 \mathrm{delG}$ & rs80338939 & p.Gly12Valfs & Pathogenic $^{c}$ & BEB, CEU, CLM, FIN, GBR, IBS, MXL, TSI \\
\hline c. $101 \mathrm{~T}>\mathrm{C}$ & rs35887622 & p.Met34Thr & Pathogenic $^{\mathrm{d}}$ & $\begin{array}{l}\text { ASW, CEU, CLM, FIN, GBR, IBS, MXL, } \\
\text { PUR, TSI }\end{array}$ \\
\hline c. $109 \mathrm{G}>\mathrm{A}$ & rs72474224 & p.Val37Ile & Pathogenic $^{c}$ & $\begin{array}{l}\text { CDX, CHB, CHS, CLM, JPT, KHV, } \\
\text { LWK, MXL }\end{array}$ \\
\hline c. $186 \mathrm{C}>\mathrm{T}$ & rs397516869 & p.Asn62 = & Unknown & n.a. \\
\hline c. $225 \mathrm{G}>\mathrm{T}$ & rs149137695 & p. $\operatorname{Arg} 75=$ & Unknown & n.a. \\
\hline c. $380 \mathrm{G}>\mathrm{A}$ & rs111033196 & p.Arg $127 \mathrm{His}$ & Controversial & BEB, GBR, GIH, ITU, KHV, PJL, STU, TSI \\
\hline c. $457 \mathrm{G}>\mathrm{A}$ & rs111033186 & p.Val153Ile & Controversial & BEB, CLM, GIH, ITU, PJL, STU, TSI \\
\hline c. $499 \mathrm{G}>\mathrm{A}$ & rs111033360 & p.Val167Met & $\begin{array}{l}\text { Likely } \\
\text { pathogenic }^{\mathrm{e}}\end{array}$ & LWK \\
\hline c. $* 78 \mathrm{~A}>\mathrm{T}$ & rs576671031 & 3'UTR & Unknown & $\mathrm{ACB}$ \\
\hline c. $* 84 \mathrm{~T}>\mathrm{C}$ & rs3751385 & 3'UTR & Polymorphism $^{\mathrm{f}}$ & All populations \\
\hline c. $* 96 \mathrm{~A}>\mathrm{G}$ & rs 188027627 & 3'UTR & Unknown & ESN, LWK \\
\hline c. $* 104 \mathrm{~A}>\mathrm{T}$ & rs7337074 & 3'UTR & Polymorphism $^{\mathrm{b}}$ & $\begin{array}{l}\text { ACB, ASW, CLM, ESN, GWD, IBS, LWK, } \\
\text { MSL, MXL, PEL, PUR, YRI }\end{array}$ \\
\hline c. $* 111 \mathrm{C}>\mathrm{T}$ & rs7329857 & 3'UTR & Polymorphism $^{\text {b }}$ & $\begin{array}{l}\text { ACB, ASW, CLM, ESN, GIH, GWD, IBS, } \\
\text { LWK, MSL, MXL, PEL, PUR, YRI }\end{array}$ \\
\hline
\end{tabular}

Unknown-The authors consider that there are still insufficient data in the literature, including this study, for inferring benignity or pathogenicity of the variant.

Controversial-In view of the conflicting data in the literature regarding the pathogenicity of the variant, the authors are unable to classify it as either benign (polymorphism) or pathogenic.

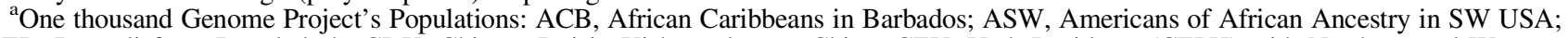
BEB, Bengali from Bangladesh; CDX, Chinese Dai in Xishuangbanna, China; CEU, Utah Residents (CEPH) with Northern and Western European Ancestry; CHB, Han Chinese in Bejing, China; CHS, Southern Han Chinese; CLM, Colombians from Medelin, Colombia; ESN, Esan in Nigera; FIN, Finnish in Finland; GBR, British in England and Scotland; GIH, Gujarati Indian from Houston, Texas; GWD, Gambian in Western Divisions in The Gambia; IBS, Iberian population in Spain; ITU, Indian Telugu from the UK; JPT, Japanese in Tokyo, Japan; KHV, Kinh in Ho Chi Minh City, Vietnam; LWK, Luhya in Webuye, Kenya; MSL, Mende in Sierra Leone; MXL, Mexican Ancestry from Los Angeles USA; PEL, Peruvians from Lima, Peru; PJL, Punjabi from Lahore, Pakistan; PUR, Puerto Ricans from Puerto Rico; STU, Sri Lankan Tamil from the UK; TSI, Toscani in Italy; YRI, Yoruba in Ibadan, Nigera.

${ }^{\mathrm{b}}$ Significant allelic frequencies in some 1000 Genome Project's populations and homozygous genotypes have been observed in normalhearing controls.

${ }^{\mathrm{c}}$ The pathogenicity of the variant is well established in the literature.

${ }^{\mathrm{d}}$ In spite of OMIM considering this variant as one of unknown significance (www.omim.org/entry/121011), we considered it as pathogenic based on several reports from the literature.

${ }^{\mathrm{e}}$ Based on in silico analytic tools as assessed at the Deafness Variation Database (http://deafnessvariationdatabase.org/).

${ }^{\mathrm{f}}$ This variant is clearly a polymorphism based on the genotypic frequencies available for several populations (dbSNP at NCBI).

n.a., not available. 


\section{Discussion}

HL remains an important global health burden. We highlight and contextualize the salient findings and conclusions from the present study.

\section{Coding variants of GJB2}

Pathogenic and controversial variants. In this study, with regard to São Tomé and Príncipe's population, we have identified the pathogenic c.35delG, p.Met34Thr and p.Val37Ile mutations, and the controversial p.Arg127His and p.Val153Ile variants (Table 4). These five sequence changes are the most commonly found in patients from Eurasian and Mediterranean populations, and all have been previously found in Portuguese HL patients (Matos et al., 2013). Thus, a non-Sub-Saharan genetic influence in São Tomé and Príncipe's population is suggested, and the European genetic influx reported by Tomás et al. (2002), most likely due to admixture with the Portuguese, is supported by our results.

p.Val167Met: a likely recessive pathogenic variant. As regards the p.Val167Met variant, it has been previously found, in heterozygosity, in four Kenyans with prelingual, nonsyndromic HL (Gasmelseed et al., 2004) and in one Cameroonian HL patient (Bosch et al., 2014b). This variant has also been observed in the Luhya (Webuye, Kenya) population (Table 4), from the 1000 genomes project (www.1000genomes .org/), in heterozygosity and with an allelic frequency of $0.51 \%$. The p.Val167Met variant, carried by one control individual from our sample, was also present in 1 out of 188 African-American control chromosomes (Samanich et al., 2007). The p.Val167Met variant has also been identified, in heterozygosity, in two studies, including African-American subjects, but the ethnicities of the carriers were not disclosed (Putcha et al., 2007; Ross et al., 2007). In silico analytic tools, as accessed at the Deafness Variation Database (http:// deafnessvariationdatabase.org/), suggest the pathogenicity of p.Val167Met. Taking all together, p.Val167Met seems to be a recessive pathogenic variant of Sub-Saharan African origin.

Synonymous variants. We have identified two synonymous variants as well. The p.Arg75 = variant was identified in one bilateral HL patient and in five controls (5/177 alleles $=1.41 \%$ ), and the p.Asn62=variant was found in one control individual $(1 / 354$ alleles $=0.28 \%)$. Noteworthy, these two synonymous $G J B 2$ coding variants, of as yet unknown significance (Table 4), are present in Sub-Saharan African and Eastern Asian populations (Bosch et al., 2014b; Chen et al., 2014; Gasmelseed et al., 2004; Han et al., 2008; Mingkun et al., 2007; Trotta et al., 2011).

\section{Noncoding variants of GJB2}

As expected, the São Tomé and Príncipe's population harbors some GJB2 noncoding variants that are shared mainly with Sub-Saharan African populations and populations of a Sub-Saharan African ancestry. A statistically significant difference in genotypic distribution regarding the c.*84T $>C$ variant was observed between controls and patients with severe or profound bilateral HL $(p=0.005)$.

The most common of the 10 noncoding variants genotyped in the subjects of our sample, c. $* 84 \mathrm{~T}>\mathrm{C}$, is also found in the project's populations of all the 1000 genomes (Table 4) and was observed in the control sample with an allelic frequency close to those of the Sub-Saharan populations as well as the Americans of African ancestry, Han Chinese and Japanese populations.

The c.*84T $>$ C variant (rs3751385) has been previously found to be significantly associated with HL (Dickson et al., 2010), in the context of demonstrating the creation of synthetic genome-wide associations by rare variants. In our sample, both allele $\mathrm{T}$ and $\mathrm{C}$ at the $\mathrm{c} . * 84$ are common but a synthetic association between one or both c.*84 alleles and HL cannot be excluded. A larger sample would be necessary to further investigate a putative association of variants at position c. $* 84$ with HL in São Tomé and Príncipe's population.

As regards the noncoding variants c. $-22-12 \mathrm{C}>\mathrm{T}$ and c. $-15 \mathrm{C}>\mathrm{T}$, they were identified in controls with allelic frequencies of $17.95 \%$ and $6.33 \%$, respectively. These polymorphisms are the most frequent in Sub-Saharan African populations and in populations of a Sub-Saharan African ancestry (www.1000genomes.org/; Table 4).

The c.-6T $>$ A variant, observed in controls with an allelic frequency of $1.14 \%$, is also the most frequent in Sub-Saharan African populations and in populations of a Sub-Saharan African ancestry (www.1000genomes.org/). To the extent of our knowledge, this variant, of an unknown effect (Table 4), has only been described in the heterozygous state (AlQahtani et al., 2010; Shan et al., 2010; Tang et al., 2006; www.1000genomes.org/).

Some other noncoding variants, of an unknown effect (Table 4), were rarely observed in this study. The c.-7G $>A$, c. $-14 \mathrm{G}>\mathrm{A}, \mathrm{c} . * 78 \mathrm{~A}>\mathrm{T}$, and c. $* 96 \mathrm{~A}>\mathrm{G}$ variants were each observed in our sample only once or twice, in heterozygosity. The c.*96A $>\mathrm{G}$ variant was observed only in the Luhya (Webuye, Kenya) and Essan (Nigeria) populations, in the heterozygous form. The $\mathrm{c}$ * $78 \mathrm{~A}>\mathrm{T}$ variant has been observed only in the African Caribbean (Barbados) population (Table 4), also in the heterozygous form. No populational data are available for the c. $-7 \mathrm{G}>\mathrm{A}$ and c. $-14 \mathrm{G}>\mathrm{A}$ variants (Table 4).

\section{GJB6 deletions}

None of the two large GJB6 deletions has been identified in São Tomé and Príncipe. These results are similar to those obtained in previous studies on HL patients from SubSaharan African populations and Sub-Saharan African ancestry populations.

The del(GJB6-D13S1854) is not particularly frequent in Portuguese NSSHL patients ( $0.4 \%$ of the patients' alleles), and the del(GJB6-D13S1830) seems to be fairly rare in these patients (Chora et al., 2010; Matos et al., 2013). Given the relatively low degree of European (mainly Portuguese) admixture of São Tomé and Príncipe's population (Tomás et al., 2002), it is likely that none of the GJB6 deletions plays a relevant role in NSSHL in São Tomé and Príncipe's population, as suggested by our data.

\section{Conclusions}

The role of GJB2 coding mutations in NSSHL in São Tomé and Príncipe seems to be of little significance. Our study, however, suggests the existence of pathogenic, and likely pathogenic, coding variants in São Tomé and Príncipe's population. Thus, although no biallelic HL patients have been 
identified in our sample, the eventual occurrence of GJB2related HL in this population should not be disregarded. The role of the GJB6 large deletions in NSSHL in São Tomé and Príncipe, if any, is predicted by this study to be small.

\section{Acknowledgments}

The authors dedicate this article to Professor Jorge Gaspar, unfortunately not with them anymore, whose idea it was to include genetic etiology in this work. To him, for the present study and beyond, the authors offer their heartfelt gratitude. The authors want to thank all the people from São Tomé and Príncipe who had volunteered for the present study. The authors are also grateful to the Instituto Marquês de Valle Flôr, which made possible the selection, recruitment, and enrollment of the participants in this study.

\section{Author Disclosure Statement}

The authors declare that no conflicting financial interests exist.

\section{References}

Al-Qahtani MH, Baghlab I, Chaudhary AG, et al. (2010). Spectrum of GJB2 mutations in a cohort of nonsyndromic hearing loss cases from the Kingdom of Saudi Arabia. Genet Test Mol Biomarkers 14, 79-83.

Bosch J, Lebeko K, Nziale JJN, et al. (2014a). In search of genetic markers for nonsyndromic deafness in Africa: A study in cameroonians and black South Africans with the GJB6 and GJA1 candidate genes. OMICS 18, 481-485.

Bosch J, Noubiap JJ N, Dandara C, et al. (2014b). Sequencing of GJB2 in cameroonians and black South Africans and comparison to 1000 genomes project data support need to revise strategy for discovery of nonsyndromic deafness genes in Africans. OMICS 18, 705-710.

Chen K, Zong L, Liu M, et al. (2014). Developing regional genetic counseling for southern Chinese with nonsyndromic hearing impairment: A unique mutational spectrum. J Transl Med 12, 64.

Chora JM, Matos TM, Martins JF, et al. (2010). DFNB1-associated deafness in Portuguese cochlear implant users: Prevalence and impact on oral outcome. Int J Pediatr Otorhi 74, 1135-1139.

del Castillo I, Moreno-Pelayo MA, del Castillo FJ, et al. (2003). Prevalence and evolutionary origins of the del(GJB6D13S1830) mutation in the DFNB1 locus in hearing-impaired subjects: A multicenter study. Am J Hum Genet 73, 1452-1458.

del Castillo FJ, Rodríguez-Ballesteros M, Alvarez A, et al. (2005). A novel deletion involving the connexin-30 gene, del(GJB6-d13s1854), found in trans with mutations in the GJB2 gene (connexin-26) in subjects with DFNB1 nonsyndromic hearing impairment. J Med Genet 42, 588-594.

Dickson SP, Wang K, Krantz I, et al. (2010). Rare variants create synthetic genome-wide associations. PLoS Biol 8, e1000294.

Gasmelseed NMA, Schmidt M, Magzoub MMA, et al. (2004). Low frequency of deafness-associated GJB2 variants in Kenya and Sudan and novel GJB2 variants. Hum Mutat 23, 206-207.

Gorga MP, Worthington DW, Reiland JK, et al. (1985). Some comparisons between auditory brainstem response thresholds, latencies, and the pure-tone audiogram. Ear Hear 6, 105-112.

Gorga MP, Johnson TA, Kaminski JK, et al. (2006). Using a combination of click- and toneburst-evoked auditory brainstem response measurements to estimate pure-tone thresholds. Ear Hear 27, 60-74.
Han SH, Park HJ, Kang EJ, et al. (2008). Carrier frequency of GJB2 (connexin-26) mutations causing inherited deafness in the Korean population. J Hum Genet 53, 1022-1028.

INE. (2014). População portadora de deficiência IV RGPH2012- S. Tomé. (I. N. de Estatística, Ed.). São Tomé, São Tomé e Príncipe: Instituto Nacional de Estatística.

Javidnia H, Carson N, Awubwa M, et al. (2014). Connexin gene mutations among Ugandan patients with nonsyndromic sensorineural hearing loss. Laryngoscope 124, E373-E376.

Jerger J, and Mauldin L. (1978). Prediction of sensorineural hearing level from the brainstem evoked response. Archives of Otolaryngology (Chicago IL, 1960), 104, 456-461.

Kabahuma RI, Ouyang X, Du LL, et al. (2011). Absence of GJB2 gene mutations, the GJB6 deletion (GJB6-D13S1830) and four common mitochondrial mutations in nonsyndromic genetic hearing loss in a South African population. Int J Pediatr Otorhi 75, 611-617.

Lasisi AO, Bademci G, Foster IIJ, et al. (2014). Common genes for non-syndromic deafness are uncommon in Sub-Saharan Africa: A report from Nigeria. Int J Pediatr Otorhi 78, 1870-1873.

Matos TD, Simoes-Teixeira H, Caria H, et al. (2010). The controversial p.Arg127His mutation in GJB2: Report on three Portuguese hearing loss family cases. Genet Test Mol Biomarkers 14, 141-144.

Matos TD, Simões-Teixeira H, Caria H, et al. (2013). Spectrum and frequency of GJB2 mutations in a cohort of 264 Portuguese nonsyndromic sensorineural hearing loss patients. Int $\mathrm{J}$ Audiol 52, 466-471.

Ming-kun H, Dong-yi H, Yu-fen G, et al. (2007). Screening of GJB2 mutations in Chinese population. J Otol 2, 18-22.

Neves CA. (1989). São Tomé e Príncipe na segunda metade do séc. XVIII. Centro de Estudos de História do Atlântico. $1^{\mathrm{a}}$ Edição, Funchal.

Putcha GV, Bejjani BA, Bleoo S, et al. (2007). A multicenter study of the frequency and distribution of GJB2 and GJB6 mutations in a large North American cohort. Genet Med 9, 413-426.

Ross SA, Novak Z, Kumbla RA, et al. (2007). GJB2 and GJB6 mutations in children with congenital cytomegalovirus infection. Pediatr Res 61, 687-691.

Samanich J, Lowes C, Burk R, et al. (2007). Mutations in GJB2, GJB6, and mitochondrial DNA are rare in African American and Caribbean Hispanic individuals with hearing impairment. Am J Med Genet A 143A, 830-838.

Shan J, Chobot-Rodd J, Castellanos R, et al. (2010). GJB2 mutation spectrum in 209 hearing impaired individuals of predominantly Caribbean Hispanic and African descent. Int J Pediatr Otorhi 74, 611-618.

Smith RJH, and Van Camp G. (1998). Nonsyndromic hearing loss and deafness, DFNB1. 1998 Sep 28 [Updated 2014 Jan 2]. In: Pagon RA, Adam MP, Ardinger $\mathrm{HH}$, et al., eds. GeneReviews ${ }^{\circledR}$ [Internet]. Seattle (WA): University of Washington, Seattle; 1993-2016. www.ncbi.nlm.nih.gov/books/ NBK1272/ Accessed 5 July, 2016.

Tang HY, Fang P, Ward PA, et al. (2006). DNA sequence analysis of GJB2, encoding connexin 26: Observations from a population of hearing impaired cases and variable carrier rates, complex genotypes, and ethnic stratification of alleles among controls. Am J Med Genet A 140A, 2401-2415.

Tomás G, Seco L, Seixas S, et al. (2002). The peopling of São Tomé (Gulf of Guinea): origins of slave settlers and admixture with the Portuguese. Hum Biol 74, 397-411.

Trotta L, Iacona E, Primignani P, et al. (2011). GJB2 and MTRNR1 contributions in children with hearing impairment from Northern Cameroon. Int J Audiol 50, 133-138. 
Van der Drift JF, Brocaar MP, and van Zanten GA. (1987). The relation between the pure-tone audiogram and the click auditory brainstem response threshold in cochlear hearing loss. Audiology. Official Organ of the International Society of Audiology, 26, 1-10.

World Health Organization. (2013). Prevention of blindness and deafness-Grades of hearing impairment. WHO. 2013. www .who.int/pbd/deafness/hearing_impairment_grades/en/. Accessed July 4, 2016.
Address correspondence to: Helena Caria, PhD School of Health Polytechnic Institute of Setubal ESS/IPS—Campus do IPS Estefanilha Setubal 2914-503 Portugal

E-mail: helena.caria@ess.ips.pt

\section{Abbreviations Used}

ANSI $=$ American National Standards Institute

DNA $=$ deoxyribonucleic acid

GJB2 $=$ gap junction protein beta 2

GJB6 = gap junction protein beta 6

$\mathrm{HL}=$ hearing loss

NCBI = National Center for Biotechnology Information

NMS $\mid$ UNL $=$ NOVA Medical School $\mid$ Universidade Nova de Lisboa

$\mathrm{NSHL}=$ nonsyndromic hearing loss

NSSHL $=$ nonsyndromic sensorineural hearing loss

$\mathrm{PCR}=$ polymerase chain reaction

$\mathrm{WHO}=$ World Health Organization 